\title{
Impact of Dietary Counselling to Improve Nutritional Status of Hemodialysis Patients
}

\author{
Saeed Razaq ${ }^{1}$, Khudija Nayab ${ }^{2}$, Anam Javed Mirza ${ }^{3}$ \\ 1,2. Post Graduate Trainee and Medical Officer Hayatabad Medical Complex Peshawar, Pakistan \\ 3. House Officer Lahore General Hospital, Lahore
}

\begin{abstract}
Proper nutrition may reverse the malnutrition and can modulate renal function in hemodialysis patients. In majority of the dialysis units in Pakistan, nutritional advice is given by health professionals working in dialysis. We compared the impact of dietary counseling by a renal dietitian, on nutritional status with that by health professionals working in dialysis units in patients undergoing maintenance hemodialysis. Nutritional assessments were made using subjective global assessment (SGA) scale, which combines assessment of intake, physical findings, and functional status. Two hundred and seventy-seven patients undergoing hemodialysis from two renal care units in Hayatabad Medical Complex Peshawar and Lahore Gernal Hospital Lahore Pakistan, were enrolled (138 patients in control group, 139 in experimental group). In the experimental group, patients were given repeated dietary counseling by a renal dietician, whereas control group patients were provided with the necessary nutritional information by another health professional. Detailed nutritional, biochemical, and SGA assessment were done on all of them at the beginning and completion of study after 6 months. Patients were categorized as well-nourished $(\mathrm{WN})(\mathrm{SGA}=1-14)$, mild to moderate malnourishment $(\mathrm{MMM})(\mathrm{SGA}=15-35)$, and severe malnutrition $(\mathrm{SM})(\mathrm{SGA}=36-49)$. In the present study, the overall malnutrition rate at baseline was $95.3 \%$, and it dropped down to $91.7 \%$ after 6 months after nutritional counseling. In the experimental group, malnutrition status decreased from $97.2 \%$ to $89.8 \%$, whereas in the control group, malnutrition situation remained same. Compared to baseline, in the control group, there was no improvement in the WN group. However, a shift has been observed from MMM group to SM group suggesting more number of patients are becoming malnourished. Contrarily, in the experimental group, an improvement of $+7.2 \%$ in $\mathrm{WN}$ group and $+14.3 \%$ in MMM group and a drop of $-21.6 \%$ in severe malnourished group suggesting more number of patients gaining nutrition. The present study observed a significant improvement in nutritional status of patients who received counseling by the renal dietician. The reduction in SGA score was independent of reductions in serum creatinine and blood urea levels
\end{abstract}

Keywords: Dietary Counselling, Nutritional Status, Hemodialysis Patients

DOI: $10.7176 / \mathrm{JMPB} / 55-16$

Publication date:May $31^{\text {st }} 2019$

\section{Introduction}

End-stage renal disease (ESRD) is a major public health problem, and its incidence and prevalence are increasing worldwide.[1,2] Malnutrition was regarded as the late complication of chronic renal failure. It varies between $23 \%$ and $76 \%$ of patients who were undergoing maintenance hemodialysis.[3,4] Several small and large-scale cohort studies have revealed that protein-energy malnutrition (PEM) was associated with increased morbidity, mortality, and impaired quality of life.[5-7]Protein-energy wasting (PEW) in these patients may be a consequence of both a decreased dietary intake or increased nutrient losses.[6] Reports have suggested a strong association between nutrition and clinical outcome in hemodialysis patients.[8-10] It is important to estimate the individual's nutritional status, detect malnutrition, start nutritional counseling, prescribe an appropriate diet, protein enriched food, oral and parenteral nutritional supplements. Nutritional education and dietary counseling for patients with renal disease play a significant role in the preservation of renal function and overall well-being of the renal patient since dietary protein intake can modulate renal function.[11] In the majority of the dialysis units in Pakistan, nutritional information is given by health professionals rather than renal dietician. However, such information may not be able to provide practical nutritional education, where patients can make one small change at a time in their food choices.[12] We compared the impact of dietary counseling by a renal dietitian under the close monitoring of nephrologists' versus health professionals working in dialysis units on nutritional status in patients undergoing hemodialysis. 


\section{Methods:}

A total of 277 patients from two renal care units (138 patients in control group, patients were undergoing hemodialysis in government hospital, 139 in the experimental group where patients from an exclusive kidney hospital) participated in this study. Independent Ethics Committee cleared the study protocol. Patients were enrolled once written informed consent was obtained. Both male and female patients above 18 years of age, with chronic kidney disease (CKD) stage-V and receiving two or three hemodialysis sessions per week for at least 6 months, were included in the study. Patients who were not willing to comply with study procedures, not willing to take high-protein diet as suggested, having the history of malabsorption syndromes and seropositive for retrovirus infection were excluded from the study.In the experimental group, patients were given repeated dietary counseling by a renal dietician, whereas control group patients were provided with the necessary nutritional information by another health professional. The primary intention of advice was to make each patient to increase their protein intake to $1.2 \mathrm{~g} / \mathrm{kg}$ /day.Detailed demographic, clinical, nutritional, biochemical, and subjective global assessment (SGA) were completed at the beginning of the study and after 6 months. The SGA is easy and rapidly conducted tool used by nurses, dietitians, or physicians to assess PEM in chronic dialysis patients.[13] SGA has a set of questions relating to a history part $(60 \%)$ and physical examination $(40 \%)$. It assesses four components of medical history (i.e., weight change, dietary intake, gastrointestinal symptoms, and functional capacity) and three components of physical examination (loss of subcutaneous fat, muscle wasting and edema). A fully quantitative score consists of seven parts with the total score ranging between 7 (normal) and 49 (severely malnourished). Patients were categorized as well-nourished (WN) (SGA = 1-14), mild to moderate malnourishment $(\mathrm{MMM})(\mathrm{SGA}=15-35)$, severe malnutrition $(\mathrm{SM})(\mathrm{SGA}=36-49)$. [13, 14]In the control group, dialysis technicians gave instructions to patients regarding fluid and salt restriction, and to practice leaching method to decrease potassium restrict. However, these dietary advices were verbal, not at regular intervals and usually lasted less than five minutes. Contrary to this, the dietary counseling in experimental group, was given two times in a month by renal dietician. It was tailored for each level of malnutrition by assessing their dietary patterns using food frequency questionnaire and 24 hour recall method. The advices given to the patients also included correction of electrolyte imbalance, high protein intake, fluid restriction, knowledge on allowed and restricted foods, disadvantages of leaching methods, and tips for maintain thirst. The average consultation time for each patient was 10-15 min. The dietary advice to the dialysis patients were either one-to-one counselling or group counselling. They also provided practical classes on nutritional education to the patient's family and friends via posters, newsletters and report cards in a simple format. After dietary counseling by renal dietician in the experimental group, all the patients who had a habit of alcoholism stopped alcohol intake, around $20 \%$ of patients had improvement in appetite, $30 \%$ of patients restricted water intake to one liter, and such an observation was not seen in the control group. Every day pulse consumption behavior in the control group was marginal when compared to experimental group. Cola consumption was increased in the control group. Chocolate consumption was increased in experimental group. Leaching method practice was decreased to $5 \%$ in experimental group while in the control group it increased to approximately $38 \%$.Statistical analysisData collected in predesigned case record forms. Data management such as cleaning, sorting, storing, and tabulating was performed using Microsoft Excel Spreadsheet-2007. Statistical computations were performed using SPSS for Windows, Version 16.0. Chicago, SPSS Inc. Mean \pm standard deviation, actual numbers, and were calculated for continuous and category variables, respectively. Chi-square test was used appropriately. A P $<0.05$ was considered statistically significant.Sample size calculation - A 5\% reduction in SGA scores of WN patients in the experimental group was anticipated over the control group based on our pilot data. The study was designed with $80 \%$ power, an alpha error of 0.05 , and beta error of $20 \%$. In addition, we increased the samples size by $20 \%$ to account for the loss in patient follow-up and data unavailability. A total of 150 patients were planned to be recruited for each group.

\section{Results:}

A total of 277 ESRD patients undergoing maintenance hemodialysis were studied. Out of them, $77.3 \%$ were male and remaining $22.7 \%$ were female. The majority of (31\%) them were in the age group $41-50$ years, followed by $22 \%$ were in the age group of 51-60 years. $47.3 \%$ were illiterates. $79 / 277$ (28.5\%) had diabetes mellitus and 238/277 (86\%) had hypertension, and these two major risk factors might have contributed to the development of ESRD in our patients. $92.5 \%$ of the patients were undergoing dialysis $<3$ years [Table 1]. The financial status and education was significantly lower in control group than experimental group $(\mathrm{P}<0.0001)$. The only reason for exclusion from analysis was death. Twenty-six patients were excluded in control group and 23 in experimental group. There were no lost to follow-up.Duration and frequency of dialysis, drugs to control blood pressure and sugar, hormone supplementation to augment hemoglobin production, calcium/iron supplementation were similar across both the groups $(\mathrm{P}>0.05)$ [Table 2]. At baseline, energy intake by the 
control group was significantly low as compared to experimental group $(\mathrm{P}<0.0001)$. However, protein intake between these groups was statistically similar $0.7 \mathrm{~g} / \mathrm{kg} /$ day in the control group versus $0.78 \mathrm{~g} / \mathrm{kg} / \mathrm{day}$ in the experimental group.It can be seen from Table 3 that, six months after diet counseling, patients in the experimental group had a substantial increase in energy and protein intake compared with control group $(2125.14 \pm 302.19$ vs. $1330.17 \pm 238.46 ; \mathrm{P}<0.0001)$ and $(1.2$ vs. $0.7 \mathrm{~g} / \mathrm{kg} / \mathrm{day}, \mathrm{P}<0.0001)$, respectively. Dietary counseling has improved serum albumin a marker of nutrition in both the groups. However, the magnitude of improvement in the serum albumin between two groups was not significant $(\mathrm{P}>0.05)$. SGA score a composite marker of nutritional status significantly improved in the experimental group, whereas it remained more or less same in the control group. We also observed an unexplained significant drop in blood urea and serum creatinine in experimental group -40.66 versus $-0.31 \mathrm{mg} / \mathrm{dl}(\mathrm{P}<0.0001)$ and -3.67 versus $+0.72 \mathrm{mg} / \mathrm{dl}(\mathrm{P}<0.0001)$, respectively as compared to control group.In the present study, the overall malnutrition rates at baseline were $95.3 \%$, and it dropped down to $91.7 \%$ after 6 months after nutritional counseling. In experimental group, malnutrition status decreased from $97.2 \%$ to $89.8 \%$ after 6 months, whereas in control group, malnutrition status remained same even after 6 months. Analysis of Table 3 reveals that as compared to baseline, in the control group, there was no improvement in the WN group. However, a shift has been observed from MMM group to SM group suggesting more number of patients were becoming severe malnourished. Contrarily, in the experimental group, an improvement of $+7.2 \%$ in $\mathrm{WN}$ group and $+14.3 \%$ in MMM group and a drop of $-21.6 \%$ in severe malnourished group suggested more number of patients receiving real nourishment [Figure 1]. It can be appreciated from the results that changes in the experimental group alone contributed to the overall improvement.Finally, we performed correlations [Table 4] between SGA scores and markers of disease and length of dialysis to test whether the observed reduction in SGA can be solely due to dietary counseling and the high-protein diet. SGA did not correlate with serum creatinine, blood urea, serum albumin, hemoglobin, and duration of hemodialysis. Nonetheless, serum creatinine inversely correlated with serum albumin, blood urea, and hemoglobin. From the above findings, it can be suggested that the improvement in nutritional changes was independent of changes in markers of renal disease.In addition, to assess which component of SGA has changed significantly before and after diet counseling, we compared the absolute change in SGA scores between control and experimental group using unpaired t-test [Table 5] and found that, there was no significant difference in change in weight which is a component of SGA $(\mathrm{P}>0.05)$. The remaining other components include change in diet, gastrointestinal symptoms, functional capacity, loss of subcutaneous fat, muscle wasting, and edema $(\mathrm{P}<$ $0.05)$. 
Table 1: Distribution of patients according to sociodemographic variables

\begin{tabular}{lccc}
\hline $\begin{array}{l}\text { Age } \\
\text { (years) }\end{array}$ & $\boldsymbol{n}(\%)$ & Dialysis duration (years) & $\boldsymbol{n}(\%)$ \\
\hline $21-30$ & $20(7.2)$ & $<1$ & $152(55)$ \\
$31-40$ & $52(18.8)$ & $1-2$ & $65(23.5)$ \\
$41-50$ & $86(31)$ & $2-3$ & $39(14)$ \\
$51-60$ & $61(22)$ & $3-4$ & $14(5)$ \\
$61-70$ & $51(18.4)$ & $4-5$ & $4(1.5)$ \\
$>70$ & $7(2.6)$ & $>6$ & $3(1)$ \\
Total & $277(100)$ & Total & $277(100)$ \\
Male & $214(77.3)$ & Female & $63(22.7)$ \\
\hline
\end{tabular}

\begin{tabular}{|c|c|}
-10 \\
-10
\end{tabular}

Figure 1: Percentage change in nourishment compared to baseline 


\begin{tabular}{|c|c|c|c|c|}
\hline Parameters & Visit & Control (C) $(n=138)$ & Experimental (E) $(n=139)$ & $P$ value (C vs. E) \\
\hline \multirow[t]{4}{*}{ Weight (kg) } & Before (B) & $53.36 \pm 11.38$ & $57.34 \pm 10.74$ & 0.003 \\
\hline & $\operatorname{After}(\mathrm{A})$ & $53.38 \pm 11.64$ & $56.17 \pm 10.29$ & 0.035 \\
\hline & $P$ value (B vs. A) & 0.98 & 0.35 & - \\
\hline & Absolute Change & $0.02 \pm 3.4$ & $-1.17 \pm 4.95$ & 0.02 \\
\hline \multirow[t]{4}{*}{ Body mass index $\left(\mathrm{kg} / \mathrm{m}^{2}\right)$} & Before (B) & $20.27 \pm 3.73$ & $22.40 \pm 4.19$ & $<0.0001$ \\
\hline & After (A) & $20.43 \pm 3.85$ & $21.90 \pm 4.08$ & 0.20 \\
\hline & $P$ value (B vs. A) & 0.72 & 0.31 & - \\
\hline & Absolute Change & $0.16 \pm 1.6$ & $-0.5 \pm 1.74$ & 0.005 \\
\hline \multirow[t]{4}{*}{ Energy $35 \mathrm{kcal} / \mathrm{kg} /$ day $(\mathrm{kcal})$} & Before (B) & $1324.09 \pm 296.53$ & $1520.12 \pm 355.73$ & $<0.0001$ \\
\hline & After (A) & $1330.17 \pm 238.46$ & $2125.14 \pm 302.19$ & $<0.0001$ \\
\hline & $P$ value (B vs. A) & 0.84 & $<0.0001$ & - \\
\hline & Absolute Change & $6.08 \pm 259.4$ & $605 \pm 1795.8$ & $<0.0001$ \\
\hline \multirow[t]{4}{*}{ Protein intake $1.2 \mathrm{~g} / \mathrm{kg} /$ day $(\mathrm{g})$} & Before (B) & $36.45 \pm 8.27$ & $44.02 \pm 8.35$ & $<0.0001$ \\
\hline & After (A) & $36.42 \pm 7.41$ & $66.73 \pm 8.39$ & $<0.0001$ \\
\hline & $P$ value (B vs. A) & 0.97 & $<0.0001$ & - \\
\hline & Absolute Change & $-0.03 \pm 8.15$ & $22.71 \pm 9.45$ & $<0.0001$ \\
\hline \multirow[t]{4}{*}{ Fat $30 \%-35 \%(\mathrm{~g})$} & Before (B) & $13.91 \pm 5.18$ & $15.20 \pm 5.99$ & 0.046 \\
\hline & After (A) & $13.25 \pm 4.92$ & $23.28 \pm 7.27$ & $<0.0001$ \\
\hline & $P$ value (B vs. A) & 0.27 & $<0.0001$ & - \\
\hline & Absolute Change & $-0.66 \pm 5.58$ & $8.08 \pm 8.33$ & $<0.0001$ \\
\hline \multirow[t]{4}{*}{ Carbohydrates $60 \%-70 \%(\mathrm{~g})$} & Before (B) & $260.48 \pm 66.01$ & $301.41 \pm 79.97$ & 0.046 \\
\hline & After (A) & $269.47 \pm 55.67$ & $405.89 \pm 65.16$ & $<0.0001$ \\
\hline & $P$ value (B vs. A) & 0.22 & $<0.0001$ & - \\
\hline & Absolute Change & $8.99 \pm 58.86$ & $104.48 \pm 73.7$ & $<0.0001$ \\
\hline \multirow[t]{4}{*}{ SGA score } & Before (B) & $32.19 \pm 8.10$ & $32.77 \pm 7.58$ & 0.53 \\
\hline & After (A) & $33.50 \pm 8.10$ & $26.60 \pm 8.93$ & $<0.0001$ \\
\hline & $P$ value (B vs. A) & 0.17 & $<0.0001$ & - \\
\hline & Absolute Change & $1.31 \pm 4.49$ & $-6.71 \pm 7.55$ & $<0.0001$ \\
\hline \multirow[t]{4}{*}{ Blood urea (mg/dl) } & Before (B) & $152.75 \pm 51.81$ & $112.15 \pm 79.96$ & $<0.0001$ \\
\hline & After (A) & $152.44 \pm 48.97$ & $71.49 \pm 32.82$ & $<0.0001$ \\
\hline & $P$ value (B vs. A) & 0.96 & $<0.0001$ & - \\
\hline & Absolute Change & $-0.31 \pm 50.52$ & $-40.66 \pm 111.49$ & $<0.0001$ \\
\hline \multirow[t]{4}{*}{ Serum creatinine (mg/dl) } & Before (B) & $7.23 \pm 2.98$ & $9.98 \pm 4.11$ & $<0.0001$ \\
\hline & After (A) & $7.95 \pm 3.12$ & $6.31 \pm 3.16$ & $<0.0001$ \\
\hline & $P$ value (B vs. A) & 0.05 & $<0.0001$ & - \\
\hline & Absolute Change & $0.72 \pm 2.80$ & $-3.67 \pm 4.04$ & $<0.0001$ \\
\hline \multirow[t]{4}{*}{ Serum albumin (mg/dl) } & Before (B) & $3.12 \pm 0.35$ & $3.35 \pm 0.35$ & 0.10 \\
\hline & After (A) & $3.32 \pm 0.36$ & $3.56 \pm 0.36$ & 0.10 \\
\hline & $P$ value (B vs. A) & $<0.0001$ & $<0.0001$ & - \\
\hline & Absolute Change & $0.21 \pm 0.31$ & $0.21 \pm 47$ & 0.92 \\
\hline
\end{tabular}

SGA: Subjective global assessment, +: Increase, -: Decrease

Table 3: Comparison of nutritional scores between hemodialysis patients receiving normal diet (control) and protein rich diet (experimental diet)

\begin{tabular}{|c|c|c|c|c|c|c|c|c|c|c|c|}
\hline \multirow[t]{2}{*}{ Group } & \multicolumn{4}{|c|}{ Baseline } & \multicolumn{4}{|c|}{ After 6 months } & \multicolumn{3}{|c|}{$\begin{array}{l}\text { Percentage change } \\
\text { from baseline }\end{array}$} \\
\hline & $\mathbf{W N}$ & MMM & SM & Total & $\mathbf{W N}$ & ММM & SM & Total & $\mathbf{W N}$ & МММ & SM \\
\hline Control & $9(6.5)$ & $74(53.6)$ & $55(40)$ & $138(49.8)$ & $9(6.5)$ & $63(45.7)$ & $66(47.8)$ & $138(49.8)$ & +0 & -7.9 & +7.8 \\
\hline Experimental & $4(2.9)$ & $80(57.6)$ & $55(39.6)$ & $139(50.2)$ & $14(10.1)$ & $100(71.9)$ & $25(18.0)$ & $139(50.2)$ & +7.2 & +14.3 & -21.6 \\
\hline Total & $13(4.7)$ & $154(55.6)$ & $110(39.7)$ & $277(100)$ & $23(8.3)$ & $163(58.8)$ & $91(32.9)$ & $277(100)$ & +3.6 & +3.2 & -6.8 \\
\hline$P$ & \multicolumn{4}{|c|}{0.341} & \multicolumn{4}{|c|}{$<0.0001$} & \multicolumn{3}{|c|}{$<0.0001$} \\
\hline
\end{tabular}

WN (SGA=1-14), MMM (SGA=15-35), SM (SGA=36-49). Numbers in parenthesis represent percentage. +: Increase, -: Decrease,

WN: Well nourished, MMM: Mild to moderate malnourishment, SM: Severe malnutrition, SGA: Subjective global assessment 


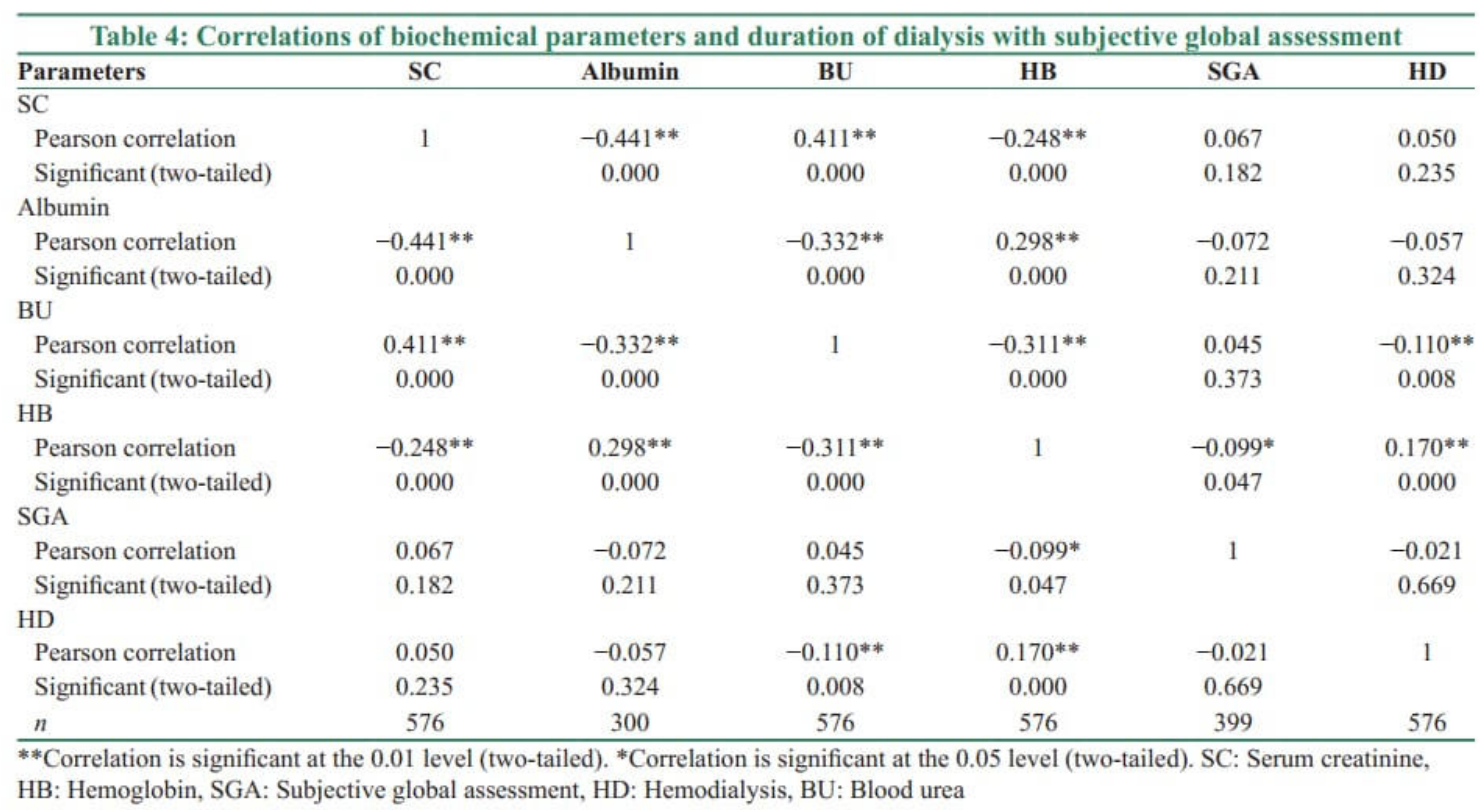

Table 5: Comparison of absolute change in subjective global assessment (SGA) scores between control and experimental group using unpaired $t$-test (+: Increase, -: Decrease)

\begin{tabular}{|c|c|c|c|c|c|c|c|}
\hline \multirow{2}{*}{$\begin{array}{l}\text { SGA } \\
\text { Parameters }\end{array}$} & \multicolumn{3}{|c|}{ Control } & \multicolumn{4}{|c|}{ Experimental } \\
\hline & Pre & Post & Absolute change (C) & Pre & Post & Absolute Change (E) & $P$ value $\mathrm{C}$ vs. $\mathrm{E}$ \\
\hline Weight & $3.41 \pm 2.08$ & $3.32 \pm 2.08$ & $-0.09 \pm 3.22$ & $3.28 \pm 2.20$ & $3.72 \pm 2.42$ & $+0.44 \pm 3.37$ & $P>0.05$ \\
\hline Diet & $4.99 \pm 2.19$ & $5.16 \pm 2.15$ & $+0.17 \pm 1.09$ & $4.14 \pm 2.14$ & $2.78 \pm 2.35$ & $-1.36 \pm 1.99$ & $P<0.05$ \\
\hline Gastro Intestinal symptoms & $1.78 \pm 1.26$ & $1.78 \pm 1.35$ & $-0.01 \pm 1.02$ & $2.12 \pm 1.64$ & $1.38 \pm 1.14$ & $-0.74 \pm 1.71$ & $P<0.05$ \\
\hline Functional capacity & $5.81 \pm 1.55$ & $5.85 \pm 1.59$ & $+0.04 \pm 0.35$ & $6.00 \pm 1.22$ & $5.56 \pm 1.60$ & $-0.44 \pm 1.31$ & $P<0.05$ \\
\hline Loss of subcutaneous fat & $5.22 \pm 1.73$ & $5.50 \pm 1.76$ & $+0.28 \pm 0.81$ & $5.73 \pm 1.51$ & $4.94 \pm 1.73$ & $-0.78 \pm 1.36$ & $P<0.05$ \\
\hline Muscle wasting & $5.17 \pm 1.78$ & $5.46 \pm 1.74$ & $+0.29 \pm 0.79$ & $5.70 \pm 1.49$ & $4.76 \pm 1.68$ & $-0.94 \pm 1.44$ & $P<0.05$ \\
\hline Edema & $5.74 \pm 1.35$ & $6.43 \pm 1.26$ & $+0.70 \pm 1.16$ & $5.86 \pm 1.70$ & $3.45 \pm 2.23$ & $-2.41 \pm 2.22$ & $P<0.05$ \\
\hline Total & $32.19 \pm 8.10$ & $33.50 \pm 8.10$ & $+1.31 \pm 4.44$ & $32.77 \pm 7.58$ & $22.82 \pm 12.45$ & $-6.17 \pm 7.53$ & $P<0.05$ \\
\hline
\end{tabular}

\section{Discussion:}

SGA has been widely used as a nutritional assessment tool and found to be highly predictive of nutrition-associated complications. It correlates the subjective aspects of medical history with the physical examination objectively. Even minor improvements or deteriorations of nutrition can be detected earlier using this 7-point scale.[15] CANUSA study suggested that a 1-unit increase in SGA equaled a $25 \%$ growth in mortality rate. In our study, the overall malnutrition rates at baseline were $95.3 \%$, reports from other studies suggests varying degrees of malnutrition which ranged from $40 \%$ to $97 \%$.[10,16-21] Such a differences in prevalence may be because of dietary and environmental diversities.Patients on maintenance hemodialysis have normal energy expenditure and approximately normal requirements for maintenance of protein balance, body weight, and body fat. An average energy intake of around $38 \mathrm{kcal} / \mathrm{kg}$ for desirable weight/day may be necessary to maintain nitrogen balance in these patients.[5,22] In the present study, only patients in the experimental group were consuming an average energy intake of $38 \mathrm{kcal} / \mathrm{kg}$. Predialysis patients appeared to have a spontaneous protein intake of $<0.7 \mathrm{~g} / \mathrm{kg} /$ day which is below the minimal recommended daily intake.[23]Diet counseling can improve nutrition for patients with hemodialysis through recommendations for adequate protein and calorie intake and nutritional supplements as needed, resulting in better nourishment in the incident dialysis. Patients were counseled for dietary protein intake of $1.2 \mathrm{~g} / \mathrm{kg} /$ day and energy intake to achieve body weight of 35 $\mathrm{Kcal} / \mathrm{kg}$ and diet chart given to patients with individual counseling. Dietitian will help to plan the right amount from each protein source for good health and strength. To this purpose, we compared the impact of dietary counseling by a renal dietitian on nutritional status with that of health professionals working in dialysis units in patients undergoing hemodialysis. It is revealed that SGA scores as the composite marker of nutritional status significantly improved in the experimental group, whereas it was status quo in the control group. Serum albumin is frequently considered as a nutritional marker and has been shown to predict outcome in ESRD patients. Every $1 \mathrm{~g} / \mathrm{dl}$ fall in serum albumin level is associated a $39 \%$ increase in the risk of cardiovascular death, the association 
between serum albumin level and mortality is highly incremental and linear.[24] In this study, nutritional counselling has improved albumin in both the groups. However, the magnitude of improvement was not statistically different between the groups. When we assessed the effect of high-protein diet upon the status of kidney functioning, we observed that there was a marginal increase in serum creatinine values in the control group which were not statistically significant. However, there was an unexplainable, yet significant drop in creatinine in the experimental group, which was in parallel with reduction in blood urea. Our finding was contrary to the usual observation, that in a dialysis patient, the steady state urea and creatinine should increase if his protein intake and muscle mass have increased, unless his clearance has been increased more significantly. However, this finding does not influence the results of the study. But needs further evaluation.Finally, to assess that the observed improvement in SGA score was solely due to dietary counseling and the high-protein diet, we performed correlation analysis between SGA scores and markers of disease and length of dialysis. We found that SGA did not correlate with serum creatinine, blood urea, serum albumin, hemoglobin, and duration of hemodialysis even though serum creatinine inversely correlated with serum albumin, blood urea, and hemoglobin. The improvement in SGA score was independent of changes in serum creatinine and blood urea levels. A constant proteinintake may also result in urea modeling. In some studies, serum albumin was meaningfully lower in the SGA malnourished group, whereas in others, serum albumin was not substantially different between the normal and the malnourished groups. Serum albumin is one of the most commonly used indicators for malnutrition among the CKD population, and although it is affected by several other factors, including inflammation, this inconsistency has raised questions of the validity of SGA.[13] PEW is harder to treat when it is severe. Hence, routine monitoring of the nutritional status of these patients allows us in early detection and treatment of PEW and prevent any further deterioration.[5] However, such an intensive monitoring may not be possible since it needs a large number of dietitians to meet the greater demand of patients.

\section{Conclusion:}

Majority of our patients undergoing maintenance hemodialysis were malnourished. There was a significant reduction in SGA scores reflecting an improvement in nutritional status of patients who received counseling by the renal dietician. This improvement in SGA score was independent of changes in serum creatinine and blood urea levels. The dietary counseling given by trained dietician is very efficient in improving the nutritional status of patients undergoing hemodialysis than by other dialysis staff.

\section{References:}

1. Eknoyan G, Lameire N, Barsoum R, Eckardt KU, Levin A, Levin N, et al. The burden of kidney disease: Improving global outcomes. Kidney Int 2004;66:1310-4.

2. Levey AS, Eckardt KU, Tsukamoto Y, Levin A, Coresh J, Rossert J, et al. Definition and classification of chronic kidney disease: A position statement from kidney disease: Improving Global Outcomes (KDIGO). Kidney Int 2005;67:2089-100.

3. Stenvinkel P, Heimbürger O, Lindholm B, Kaysen GA, Bergström J. Are there two types of malnutrition in chronic renal failure? Evidence for relationships between malnutrition, inflammation and atherosclerosis (MIA syndrome). Nephrol Dial Transplant 2000;15:953-60.

4. Alpers DH. Manual of Nutritional Therapeutics. Philadelphia USA Lippincott Williams, \& Wilkins; 2008.

5. Fouque D, Guebre-Egziabher F. An update on nutrition in chronic kidney disease. Int Urol Nephrol 2007;39:239-46.

6. Fouque D, Kalantar-Zadeh K, Kopple J, Cano N, Chauveau P, Cuppari L, et al. A proposed nomenclature and diagnostic criteria for protein-energy wasting in acute and chronic kidney disease. Kidney Int 2008;73:391-8.

7. Fouque D, Vennegoor M, Ter Wee P, Wanner C, Basci A, Canaud B, et al. EBPG guideline on nutrition. Nephrol Dial Transplant 2007;22 Suppl 2:ii45-87.

8. Ekramzadeh M, Mazloom Z, Jafari P, Ayatollahi M, Sagheb MM. Major barriers responsible for malnutrition in hemodialysis patients: Challenges to optimal nutrition. Nephrourol Mon 2014;6:e23158. 
9. Qureshi AR, Alvestrand A, Divino-Filho JC, Gutierrez A, Heimbürger O, Lindholm B, et al. Inflammation, malnutrition, and cardiac disease as predictors of mortality in hemodialysis patients. J Am Soc Nephrol 2002;13 Suppl 1:S28-36.

10. Afshar R, Sanavi S, Izadi-Khah A. Assessment of nutritional status in patients undergoing maintenance hemodialysis: A single-center study from Iran. Saudi J Kidney Dis Transpl 2007;18:397-404.

11. Mansour MA, Youssef HA, Salameh TN, Yaseen RW. Impact of education program on protein balance among hemodialysis patient. World J Med Sci 2014;11:69-77.

12. Berg J, York S, Cormier S, Warsaba D. Patient education. Incentive program to control interdialytic weight gains. J Ren Nutr 2004;14:52-9.

13. Steiber AL, Kalantar-Zadeh K, Secker D, McCarthy M, Sehgal A, McCann L. Subjective global assessment in chronic kidney disease: A review. J Ren Nutr 2004;14:191-200.

14. Kalantar-Zadeh K, Kleiner M, Dunne E, Lee GH, Luft FC. A modified quantitative subjective global assessment of nutrition for dialysis patients. Nephrol Dial Transplant 1999;14:1732-8.

15. Stojanovic M, Stojanovic D, Stefanovic V. The impact of malnutrition on mortality in patients on maintenance hemodialysis in Serbia. Artif Organs 2008;32:398-405.

16. Stenvinkel P, Heimbürger O, Paultre F, Diczfalusy U, Wang T, Berglund L, et al. Strong association between malnutrition, inflammation, and atherosclerosis in chronic renal failure. Kidney Int 1999;55:1899-911.

17. Espahbodi F, Khoddad T, Esmaeili L. Evaluation of malnutrition and its association with biochemical parameters in patients with end stage renal disease undergoing hemodialysis using subjective global assessment. Nephrourol Mon 2014;6:e16385.

18. Janardhan V, Soundararajan P, Rani NV, Kannan G, Thennarasu P, Chacko RA, et al. Prediction of malnutrition using modified subjective global assessment-dialysis malnutrition score in patients on hemodialysis. Indian J Pharm Sci 2011;73:38-45.

19. Tayyem RF, Mrayyan MT. Assessing the prevalence of malnutrition in chronic kidney disease patients in Jordan. J Ren Nutr 2008;18:202-9.

20. Tapiawala S, Vora H, Patel Z, Badve S, Shah B. Subjective global assessment of nutritional status of patients with chronic renal insufficiency and end stage renal disease on dialysis. J Assoc Physicians India 2006;54:923-6.

21. Chan M, Kelly J, Batterham M, Tapsell L. Malnutrition (subjective global assessment) scores and serum albumin levels, but not body mass index values, at initiation of dialysis are independent predictors of mortality: A 10-year clinical cohort study. J Ren Nutr 2012;22:547-57.

22. Slomowitz LA, Monteon FJ, Grosvenor M, Laidlaw SA, Kopple JD. Effect of energy intake on nutritional status in maintenance hemodialysis patients. Kidney Int 1989;35:704-11.

23. Ikizler TA, Greene JH, Wingard RL, Parker RA, Hakim RM. Spontaneous dietary protein intake during progression of chronic renal failure. J Am Soc Nephrol 1995;6:1386-91.

24. Dashti N, Einollahi N, Nabatchian F, Moradi Sarabi M, Zarebavani M. Significance of albumin and $\mathrm{C}$-reactive protein variations in 300 end stage renal disease patients in tehran university of medical sciences hospitals during year 2010. Acta Med Iran 2012;50:197-202. 